\title{
A 21 Point Unifying Hypothesis on the Etiology and Treatment of Multiple Sclerosis
}

\author{
Howard L. Weiner
}

\begin{abstract}
Multiple sclerosis (MS) is postulated to be a cell mediated autoimmune disease directed against central nervous system myelin components. Our understanding of the disease has been enhanced by a number of factors: 1) advances in our understanding of the immune system; 2) clinical trials which are beginning to identify treatments which can affect MS; 3 ) a better understanding of the clinical features of MS; and 4) advances in MRI imaging of the brain. Based on the current state of knowledge, this paper proposes a 21 point unifying hypothesis on the etiology and treatment of the disease. This hypothesis makes a series of assumptions, many of which are unproven, and is presented as a framework from which to investigate and treat the disease, not as a established biology. It is hypothesized that the underlying pathogenesis of MS is related to an inappropriate class of immune response against myelin antigens favoring proinflammatory Thl versus anti-inflammatory Th2 or Th3 type responses. Environmental and genetic factors predispose toward MS by affecting the class of response and effectiveness of treatment is also related to how it impacts on this common final pathway. Because of epitope spreading, there is not one autoantigen involved in MS and the progressive form of MS differs immunologically from the relapsing remitting form. Viruses trigger and perpetuate MS, although MS is not related to a persistent viral infection. Because MS is a multifactorial disease, there are clinical and perhaps immunological subtypes of MS and a single type of treatment is unlikely to control the disease in all patients. Thus, there will be responders and non-responders to each effective therapy and ultimately combination therapy will be required to cure the disease.
\end{abstract}

RÉSUMÉ: Une hypothèse unifiante en 21 points sur l'étiologie et le traitement de la sclérose en plaques. Il est généralement admis que la sclérose en plaques (SEP) est une maladie autoimmune à médiation cellulaire dirigée contre la composante myélinique du système nerveux central. Notre compréhension de la maladie a été favorisée par certains facteurs: 1) les progrès dans notre compréhension du système immunitaire; 2) les essais de pharmacologie clinique qui commencent à identifier des traitements qui peuvent modifier l'évolution de la SEP; 3) une meilleure compréhension des manifestations cliniques de la SEP: et 4) les progrès dans l'imagerie du cerveau par résonance magétique nucléaire. En se fondant sur l'état actuel de nos connaissances, cette conférence propose une hypothèse unifiante en 21 points sur l'étiologie et le traitement de la maladie. Cette hypothèse est basée sur une série de prémices, dont plusieurs ne sont pas encore prouvées, et elle est présentée comme un cadre pour l'investigation et le traitement de la maladie et non comme fait biologique établi. Nous émettons l'hypothèse que la pathogenèse de la SEP est reliée à une classe de réponse immunitaire inappropriée contre des antigènes de la myéline favorisant des réponses proinflammatories de type Thl versus anti-flammatoires de type Th2 ou Th3. Des facteurs environnementaux et génétiques prédisposent à la SEP en affectant la classe de réponse et l'efficacité du traitement est également relié à son impact sur cette voie finale commune. À cause de la multiplicité des épitopes, il y a plus d'un autoantigène impliqué dans la SEP et la forme progressive de la SEP diffère au point de vue immunologique de la forme récurrente-rémittente. Des virus déclenchent et perpétuent la SEP, bien que la SEP ne soit pas reliée à une infection virale persistante. Parce que la SEP est une maladie multifactorielle, il existe des sous-types cliniques et peut-être immunologiques, de SEP et il est peu probable qu'un seul type de traitement soit efficace pour contrôler la maladie. Ainsi, il y aura des répondeurs et des non répondeurs à chaque traitement et ultimement un traitement combiné sera nécessaire pour guérir la maladie.

Can. J. Neurol. Sci. 1998: 25: 93-101

Although the etiology and pathogenesis of multiple sclerosis (MS) may still be considered by many to be "unknown", the working hypothesis of most investigators is that MS is a cellmediated autoimmune disease directed against central nervous system (CNS) myelin and is related in some way to a viral infection. ' Furthermore, with recent advances in our understanding of the immune system and the demonstration that certain treatments can affect the clinical course of MS, it is now possible to approach the disease in more positive terms. Towards this end I propose a "2l point unifying hypothesis" concerning MS that attempts to identify what $I$ believe are the most important points related not only to its pathogenesis but to its treatment. Many of the points are well established, others are not. Each point has been chosen to represent what I believe is a key concept that must be considered if the disease is to be understood and effectively treated. The 21 points focus on the immune theo- ry of MS and encompass both recent investigations from our laboratory and the work of others and represent my personal bias. I present them not as proven biology, but as a framework from which to consider the disease in hope that they will spur discussion for those working in the field and provide a perspective on the illness for those not in the field. Multiple sclerosis means "many scars" and is clearly not an appropriate definition of the disease process. For the purpose of this lecture MS is defined as "recurrent inflammation of CNS white matter leading

From the Center for Neurologic Diseases, Brigham and Women's Hospital and Harvard Medical School, Boston.

RECEIVED MARCH 26, 1997. ACCEPTED IN FINAL. FORM JULY 7, 1997.

Based on the 1996 McEwan Lecture, University of Toronto.

Reprint requests to: Howard L. Weiner, Center for Neurologic Diseases, Brigham and Women's Hospital and Harvard Medical School, 77 Avenue Louis Pasteur, HIM 730, Boston, Massachusetts, USA 02115 
to myelin destruction and progressive neurologic impairment". The major question that then must be addressed is what causes this specific and recurrent inflammation and how can it be regulated.

1) MS is a cell-mediated autoimmune disease directed against myelin antigens such as MBP, PLP, and MOG. Autoantibodies may play a secondary or enhancing role (Table 1). The pathologic picture of MS is one consistent with cell-mediated immune damage to the myelin sheath. ${ }^{2-4}$ Inflammation is associated with increased expression of IFN- $\gamma$, endothelial cell activation with expression of class II and adhesion molecules, and macrophage mediated destruction of myelin via receptor-mediated endocytosis. IL-12 expression and B7.1 upregulation in the active lesions are consistent with a Thl type or cell mediated autoimmune process. ${ }^{s}$ The picture is consistent with a delayed type hypersensitivity (DTH) type response in the CNS. In support of this, cellular reactivity against several myelin antigens (MBP, PLP, MOG) has been demonstrated in the peripheral blood and cerebrospinal fluid (CSF) of MS patients. ${ }^{6-8}$ These are identical to cells that cause an MS-like disease in the animal model of MS, experimental allergic encephalomyelitis (EAE) and since they have been found in MS patients, they can be considered pathogenic cells capable of cell mediated CNS inflammation. In some instances there may be a large number of myelin autoreactive cells. ${ }^{9}$ Autoantibodies to myelin antigens have also been demonstrated in $\mathrm{MS},{ }^{10}$ and although they do not appear to be important in initiating the disease they could play an important secondary role in the disease process by causing demyelination. For example, in animals, antibody against myelin oligodendrocyte glycoprotein (MOG) has been shown to enhance demyelination when inflammation is present ${ }^{11.12}$ although alone, these antibodies have minimal pathologic effects. To date, anti-MOG antibodies have not been consistently demonstrated in patients with MS though there may be other antibodies that play a role in the process. Thus, the primary immunologic and pathologic event that causes MS is the generation of Thl type CD4+ cells that become activated, secrete IFN- $\gamma$ and other proinflammatory cytokines and are specific for antigens in the myelin sheath. Although CD8+ cells could also theoretically participate in CNS inflammation, this has not been demonstrated, and defects in CD8+ cells may be related to altered immunoregulation in the disease.

Table 1: Multiple sclerosis as a Th1-type cell-mediated autoimmune disease.

Exacerbation of MS induced by administration of IFN- $\gamma$

Elevated production of IFN- $\gamma$ and TNF in blood and CNS

Increased production of IL-12 in progressive MS

Presence of IL-12 and B7.1 in MS lesions

Similarities of MS to EAE which is a Th1 cell-mediated autoimmune disease

2) There is no single autoantigen in MS because after an immune attack on one myelin antigen, there is spreading of reactivity to other myelin antigens. For many years it was felt that identification of "the" autoantigen in MS would be the key to understanding and treating the disease. This theory was analogous to the demonstration that the acetylcholine receptor was the primary autoantigen in myasthenia gravis. This no longer is a valid assumption as it has now been demonstrated that even though CNS inflammation may be initiated by a cell meditated attack against a specific myelin antigen such as MBP, there is spreading of immune reactivity to other antigens in the target organ. This has been shown in animal models of EAE ${ }^{13-15}$ and in another prototypic organ specific autoimmune disease, diabetes in the NOD mouse. ${ }^{16,17}$ Indeed in MS, reactivity to multiple myelin autoantigens has been demonstrated ${ }^{6-8,18}$ and in the NOD mouse model of diabetes similar spreading of autoreactivity has been demonstrated with reactivity to insulin, GAD, heat shock proteins and other islet antigens. ${ }^{19}$ In MS, it is possible that spreading of reactivity among antigens and their epitopes may be responsible for causing different attacks of the disease. Furthermore, other cells such as gamma-delta cells may be recruited to the CNS once inflammation has been initiated and also participate in the pathologic inflammatory process. ${ }^{20.21}$ Thus, there is no single autoantigen that is the target of an autoimmune attack, but reactivity to multiple myelin antigens. This makes therapy directed at eliminating specific cells that react to only one myelin antigen or that have a unique $\mathrm{T}$ cell receptor problematic.

3) Initial sensitization is secondary to cross reactivity between infectious agents and CNS myelin or a self-limited infection of the brain that releases myelin antigens. There must be a triggering event or a series of triggering events that initiate the disease. The immune system evolved to protect the host against environmental pathogens and in MS the immune system is misdirected in an organ-specific fashion and attacks myelin components in the central nervous system. Thus, the initiation of the disease involves sensitization initiated by an infectious process that also confers specificity for myelin components, and this occurs via infectious agents that have components that cross react with myelin antigens, or by a selflimited infection of the brain that releases myelin antigens and results in sensitization.

4) Autoreactive $\mathbf{T}$ cells for myelin components exist in normal individuals. The major determinant of disease induction is the class of immune response that occurs when these autoreactive $T$ cells are triggered in MS patients. A major advance in our understanding of the function and regulation of the immune response is an understanding of the type or "class" of immune response that is induced (Table 2). Thl type responses are characterized by IFN- $\gamma$ secretion, and are important in the generation of delayed type hypersensitivity responses and in immune responses against viruses. Thl type responses also induce cell-mediated autoimmune diseases in animals such as EAE and, by inference, Thl type responses against myelin antigens would induce MS in humans. Administration of IFN- $\gamma$ to MS patients caused worsening of disease. ${ }^{22}$ Thl responses, however, are important in protection against certain parasitic infections (e.g., Leishmaniasis). ${ }^{23} \mathrm{Th} 2$ type responses are characterized by IL- 4 secretion, regulate $\mathrm{Th} 1$ type responses and IL4 administration is protective in EAE. ${ }^{24} \mathrm{CD} 4+$ regulatory T-cells that suppress ThI responses and primarily secrete IL-10 have also recently been described. ${ }^{25} \mathrm{Th} 3$ type responses are characterized by TGF- $\beta$ secretion and are preferentially induced following mucosal presentation of antigen. ${ }^{26}$ Furthermore, natural recovery from EAE is associated with the appearance of cells that secrete TGF- $\beta .{ }^{27,28}$ According to this paradigm, the response of a non-susceptible individual exposed to a myelin antigen is either not to respond or to generate a Th2 or Th3 
Table 2: Class of immune response.

\begin{tabular}{llll}
\hline & Th1 & Th2 & Th3 \\
\hline Cytokine $^{\mathrm{a}}$ & IFN- $\gamma$ & IL-4 & TGF- $\beta$ \\
Help & DTH/ IgG2a & IgG $1 /$ IgE & IgA \\
Suppression & Th2 & Th1 & Th1/2 \\
Immunity $^{b}$ & cell-mediated & humoral & mucosal \\
\hline
\end{tabular}

- The primary cytokine associated with each class of immune response is presented. In vivo, there can also be mixed cytokine patterns.

b Different types of immunity are favored by each type of $\mathrm{T}$ cell, but are not exclusive. Thus, although secretion of TGF- $\beta$ is favored in mucosal immunity, it is seen as part of systemic immunity as well, and Th3 responses involve cells that may secrete IL-4 and IL-10. TR1 cells are a recently described class of regulatory cells that primarily secrete IL$10 .{ }^{25}$

response which is nonpathogenic and protective, whereas in patients with MS, a pathogenic Thl type response is generated. Thus, the central concept that underlies whether MS is initiated and perpetuated, and that forms the basis for treatment, is the class of immune response (Table 3).

5) Generation of pathogenic autoreactive $T$ cells is favored both by major histocompatability complex (MHC) and non-MHC genes which determine which protein sequences an individual reacts against and the class of the immune response. $\mathrm{MHC}$ linkage to $\mathrm{MS}$ is well known with DR2 being the most closely linked factor associated with MS. ${ }^{29}$ MHC may be linked to disease in several ways: 1) it could determine the ability of a person to generate pathogenic autoreactive $T$ cells by determining which myelin peptides are presented to $\mathrm{T}$ cells; 2 ) it could determine the shape of the $\mathrm{T}$ cell repertoire at the time of $\mathrm{T}$ cell development during thymic ontogeny and during peripheral deletion; 3) it could determine the class of immune response based on the binding affinity of peptides in the MHC groove. Of note is that HLA-DR2 is linked to increased production of lymphotoxin and TNF- $\alpha$ (Th1 type cytokines) by $\mathrm{T}$ cells. ${ }^{30}$ However, it is also clear than non-MHC genes are important in determining the class of immune response to myelin antigens. For example, in animal models there are non-MHC linked genes which determine whether an animal is susceptible or not to EAE. B10.S and SJL mice are both $\mathrm{H}-2^{\mathrm{S}}$, yet only SJL animals are susceptible to EAE. ${ }^{31}$ It appears that susceptibility is determined by the class of immune response generated as when SJL are immunized with MOG or MBP in complete Freund's adjuvant, Th I type T cells are induced whereas when B10.S animals are immunized in an identical fashion, Th2 and Th3 cells are induced. ${ }^{32}$ The importance of non-MHC genes in determining the class of immune response and susceptibility or resistance to autoimmunity has also been observed in the collagen arthritis model. ${ }^{33}$ Another

Table 3: Factors which influence the class of immune responses.

Route of antigen exposure

Type of antigen

Genetics of the host

Environmental exposure

Adjuvant

Local milieu
non-MHC linked immune factor that can influence the class of immune response is the type of costimulation that occurs when antigen is presented by an antigen presenting cell to a $\mathrm{T}$ cell. ${ }^{3.4} \mathrm{~A}$ recent study supports the hypothesis that MS patients may be genetically predisposed to Thl responses as they have less IgEmediated allergic diseases which represent a Th2 mediated disease. $^{35}$

6) Environmental factors also determine the class of the immune response to myelin antigens. Other factors beside genetics must play a role in MS as it is known that identical twins are not $100 \%$ concordant for MS. ${ }^{36}$ Even though identical twins raised in the same house are exposed to a similar environment, their exposure to infectious agents is not identical and this differential environmental exposure accounts for the non-concordance rate. Differential environmental exposure impacts on the development of MS by creating an immune milieu that leads to a Thl versus a Th2 or Th3 response against myelin antigens. As discussed in point 3, environmental antigens may also lead to the generation of myelin cross reactive populations of memory cells. In addition, the age at which an individual is exposed to environmental agents may also play an important role in generating different classes of immune responses against myelin antigens. In this regard, there is some evidence that MS may be related to a viral infection that occurs at a certain time in childhood. ${ }^{37}$ Also, it is known that there are seasonal variations in MS attacks ${ }^{38}$ and we have recently found that progressive MS patients, but not controls, have increased anti-CD3 induced IFN$\gamma$ secretion in winter months. ${ }^{39}$

7) MS is not caused by a persistent viral infection although infectious agents play a crucial role in the initiation and perpetuation of the disease. One of the major questions in MS is whether a persistent virus either in the brain or in another part of the body drives the disease. ${ }^{40}$ This remains an open question and were a virus or infectious agent to be clearly identified in MS it would significantly change our thinking regarding MS. Nonetheless, based on available evidence and the unsuccessful attempts to find an MS-associated virus, I would argue that even though viruses can be associated with inflammatory demyelination in the CNS, MS is not related to an identifiable persistent virus or infection. Nonetheless, as described above, infectious agents play a crucial role in the initiating and perpetuating the disease.

8) Unexplained defects in regulatory mechanisms and/or tolerance induction exist in MS. Defects in immune regulation have been described in MS but have never been completely understood, in part because of our incomplete understanding of immune regulation and tolerance maintenance (Table 4). These defects include a number of defects in antigen-non specific suppressor mechanisms. ${ }^{41.42}$ However, a generalized defect of immune regulation or tolerance in MS does not explain the specificity of the autoimmune responses against myelin antigens, or the lack of generalized autoimmunity in MS. It may be, however, that defects in regulation or tolerance are simply related to regulation of the class of immune response generated (Th1 vs. Th2/Th3) or the state of immune activation of T cells in MS patients. There theoretically could also be defects related to innate immune responses which could also determine class of immune response or affect mechanisms associated with deletion. 
Table 4: Mechanisms of immune tolerance.

\begin{tabular}{ll}
\hline Deletion: & Death of cell \\
Anergy: & "Paralyzed" cell, lack of costimulation \\
Regulation: & Active suppression by regulatory T cells \\
\hline
\end{tabular}

9) MS is driven by $T$ cells that continually migrate into the CNS, after which local immune reactions may become established in the CNS. MS is not a localized disease of the CNS, but one that is driven by the movement of cells from the peripheral immune system into the CNS ${ }^{43}$ Thus, immune abnormalities related to the disease process can be identified and monitored in the peripheral blood of MS patients. Activated T cells are present both in the peripheral blood and the CNS of MS patients. ${ }^{44-46}$ However, local immune responses may subsequently be established in the CNS, one of the best characterized being the local production of immunoglobulin. In addition, there may be local activation of microglia. Nonetheless, migration of cells into the nervous system plays a crucial role in initiating and perpetuating the disease, especially in earlier stages of the diseases. Thus, I would postulate that without the continued migration of cells, the autoimmune process in the CNS would be attenuated or in some instances stop.

10) Subtypes of MS exist. MS is not a uniform disease, but one with different subtypes. For example, sub-types of MS may be related to immune reactivity against different myelin antigens, e.g., MBP vs. PLP vs. MOG. Studies in the EAE model suggest that differences in lesion distribution in MS may reflect differences in the myelin specificity of autoreactive T cells. ${ }^{47} \mathrm{In}$ addition, there may be different disease subtypes related to immune response genes and subtypes related to an individual's unique environmental exposure. Also spinal MS and primary progressive MS may represent a specifically unique subtype. ${ }^{48}$ The existence of different subtypes complicates the investigation and treatment of the disease.

11) Relapsing remitting MS naturally regulates itself. Treatments which augment these natural regulatory mechanisms will help the disease process. One of the clinical features of relapsing-remitting MS is that patients generally recover from an attack. This implies that there are natural regulatory mechanisms that are affecting the immune process to the benefit of the host. In the EAE model, immune mechanisms associated with recovery include apoptosis of pathogenic $T$ cells ${ }^{49}$ and a class switch from Thl to Th2/Th3 responses. ${ }^{27.50 .51}$ Evidence for a class switch during recovery from attacks is beginning to accumulate in MS as well. For example, patients who are in a recovery stage from an acute attack appear to have an increase in IL-10 secreting PLP reactive cells. ${ }^{52}$ Understanding these natural regulatory mechanisms and determining ways to augment them is likely to help the disease process.

12) When MS changes from the relapsing-remitting to the chronic progressive form, $T$ cells enter a state of chronic activation. It is the chronic progressive form of MS that usually leads to disability. There is recent evidence that changes in the immune system occur when patients change from the relapsingremitting to the chronic progressive form of the disease. These changes involve the emergence of activated $T$ cells which drive the immune system towards a Thl bias. Specifically, $T$ cells from patients with progressive forms of MS differentiate into cells that drive non-T cells to produce IL-12, a powerful inducer of Thl type responses ${ }^{53}$ and may be independent of costimulation requirements. We have also found an increase in IL-12 secreting monocytes in progressive MS. ${ }^{54}$ These results are important as they demonstrate that there is a basic difference in the peripheral immune system in progressive vs. relapsingremitting MS. By inference, there may be different responses to immunomodulatory therapy in relapsing-remitting versus chronic progressive patients. More importantly, these results imply that the study of MS should not only involve the investigation of what initiates the disease, but what occurs when the disease switches from the relapsing-remitting to the progressive form. It is also likely that changes within the CNS itself occur in the progressive form such as the development of axonal atrophy and localized CNS immune responses.

13) Although imperfect, the MRI is linked to the disease process and to the degree to which disability has accumulated. The MRI has made a major impact on our understanding of MS. It has provided a crucial diagnostic tool, demonstrated that the disease process is far more active than can be appreciated clinically, and has provided an important surrogate marker for clinical trials. ${ }^{55}$ Because there are silent areas where lesions occur, the correlation of MRI with disability cannot be perfect. However with improved understanding of the disease process as viewed by MRI and newer imaging techniques, closer correlations with disability are occurring. ${ }^{56}$ In isolated neurologic symptoms, the presence of multiple lesions on MRI has predictive value of who is at risk for the development of MS. ${ }^{57}$ Gadolinium enhancement reflects breakdown of the blood brain barrier, and we have found that the number of enhancing lesions correlates with changes in EDSS in relapsing-remitting and relapsing progressive MS whereas T2 volume correlates with disability in progressive MS. ${ }^{58}$ It also appears that disability may be more closely linked to CNS damage as measured by TI imaging and spinal cord atrophy..$^{59.60}$

14) MS is for the most part analogous to the various forms of EAE. Thus there are numerous stages in the immune cascade that the disease can be impacted. If one assumes that MS is a cell mediated CNS autoimmune disease directed against myelin components it is then analogous to EAE. ${ }^{61}$ EAE involves a well-defined series of immunologic events leading to myelin destruction and occurs in relapsing and progressive forms (Table 5). Interruption of this pathway at different stages in the cascade has an ameliorating effect on EAE. Although imperfect, EAE has served as an important working model for testing treatment approaches prior to clinical trials in MS. One of the major differences between treatment of MS and EAE is that many treatments tested in EAE are given at a restricted time during the course of EAE or prior to immunization. Also, EAE is studied in inbred strains of animals whereas MS occurs in an outbred population. Furthermore, treatment of MS requires chronic therapy of an immune system that may already be activated or in a state of differentiation. One of the unexplained differences between EAE and MS is the protective role of IFN- $\gamma$ in EAE under some circumstances, ${ }^{62-64}$ although defects in IFN- $\gamma$ suppression by CD8 cells have been observed in progressive MS. ${ }^{57}$ Nonetheless, EAE remains an important model for the study of mechanisms by which cell-mediated immunity against myelin antigens causes myelin damage and can be regulated. 
15) Many treatments have been shown to help MS. In the past it has been argued that there were no effective treatments for MS. It has now become clear that there are numerous immune modulating treatments that can affect the disease process, albeit imperfectly and not under all circumstances. ${ }^{65}$ These are listed alphabetically in Table 6 and represent my interpretation of the literature. A treatment may have a positive effect on MS even though all trials may not have demonstrated a positive clinical effect. Differences may relate to dosage schedules and differential responses in patient subgroups. For example we have found that patients with primary progressive MS do not respond as well to pulse cyclophosphamide. ${ }^{66}$ Antibiotics would not benefit all patients with pneumonia in a trial that mixed both viral and bacterial pneumonia. MS is different than other CNS diseases such as amyotrophic lateral sclerosis in which there are not many drugs that can impact on the disease process. Thus, it is important to consider MS as a disease in which immunomodulatory drugs can affect the disease process and to understand the manner in which these drugs positively impact on the disease. Furthermore, it is unlikely that each of these drugs is acting differently but that these drugs act through a limited number of pathways that ultimately impact on one final common pathway.

Table 5: EAE and immune therapy of MS.

Activation of myelin reactive $\mathrm{T}$ cells in the peripheral immune system

Migration of cells into the CNS

Recruitment of additional cells

Release of inflammatory mediators

Sensitization to new antigens in the CNS

Suppression of autoimmune response

Tissue repair

Table 6: Immune therapy which helps MS.

Azathioprine $^{81}$
Alpha-interferon $^{82}$
Beta-interferon $1 \mathrm{a}^{83}$
Beta-interferon $1 \mathrm{~b}^{84}$
Cladribine $^{85}$
Copolymer $186^{86}$
Corticosteroids
Cyclophosphamide $^{88.89}$
Cyclosporin $^{90}$
IVIg $^{91}$
Linomide $^{92.93}$
Methotrexate $^{94}$
Mitoxanthrone
Plasma Exchange
Total lymphoid irradiation $^{98}$

16) Treatments which decrease IFN- $\gamma$ producing Th1 myelin reactive cells or increase $I L-4 / 1 L-10$ or TGF- $\beta$ producing myelin reactive cells will help MS. If MS is a ThI cellmediated disease, then an increase in Thl type myelin reactive cells would be associated with worsening of disease and Th2 or Th3 type myelin reactive cells would have an ameliorating effect on the disease process. This is the theoretical basis for treatment with oral tolerance ${ }^{67}$ which increases Th3 type myelin reactive cells ${ }^{68}$ or altered peptide ligand that increases Th2 type myelin reactive cells. ${ }^{69}$ Thus one could postulate that effective treatment of MS will relate to the balance of $\mathrm{Th} 2+\mathrm{Th} 3 / \mathrm{Th} 1$ myelin reactive cells. Nonetheless, even if a treatment affects this balance it must do so with a strong enough biologic effect to impact on the disease process, something which argues for combination therapy.

17) Because of bystander suppression, knowledge of "the" antigen in MS is not required for antigen-specific therapy to be beneficial in the disease. Regulatory cells that are specific for an autoantigen secrete anti-inflammatory cytokines when they encounter the autoantigen in the target tissue, and thus will suppress inflammation in the organ under attack independent of the autoantigen. This has been termed bystander suppression $^{70}$ and has been demonstrated in a number of animal models. Thus, in the EAE model one can suppress PLP induced EAE by feeding MBP." Also in the LCMV viral model of diabetes, the LCMV protein is expressed in the pancreatic islets on the insulin promoter. When animals are infected with the virus, viral specific immune responses result in diabetes. Feeding insulin generates insulin specific regulatory cells that suppress the viral induced diabetes by migrating to the islets, reacting with insulin and secreting anti-inflammatory cytokines. ${ }^{72}$ Oral MBP can decrease stroke size in rat models by increasing TGF$\beta$ levels in the brain and suppressing inflammation associated with stroke. ${ }^{73}$ Although bystander suppression was initially described in association with mucosally induced regulatory cells, any immune manipulation that induces a class switch and Th2 or Th3 regulatory cells would have the same effect. It has been argued that this is one of the mechanisms by which copolymer 1 is effective, viz., copolymer 1 induces Th2 type cells that cross react with myelin basic protein. ${ }^{74}$ Also altered peptide ligands that induce IL- 4 and $\mathrm{T}$ cell receptor vaccination may also act via this mechanism. ${ }^{69}$ Bystander suppression solves the conundrum of having to know what the autoantigen is for antigen specific therapy.

18) For the most part, there is no "antigen non-specific" therapy. Effective treatment must ultimately affect antigenspecific myelin reactive cells. I would argue that most treatments that affect the disease process ultimately impact on antigen-specific myelin reactive cells either by decreasing IFN- $\gamma$ secreting or increasing Th2 or Th 3 myelin reactive cells. Thus, even "antigen-nonspecific" immunomodulatory treatments have their effect by affecting the balance of ThI vs. Th2/3 myelin reactive cells in the nervous system. For example, we have found that beta interferon causes a class switch by decreasing anti-CD3 induced IFN- $\gamma$ secretion and increasing IL-4 secretion $^{75}$ and beta-interferon has also been shown to increase IL$10{ }^{76}$ Unexpectedly, we have also found that cyclophosphamide, thought to be a general immunosuppressant, induces a marked immune deviation with an increase in IL- 4 and TGF- $\beta$ and a decrease in IFN- $\gamma^{75}$ and IL-12. ${ }^{54}$ In addition, there is an increase of IL-4 secreting MBP and PLP specific cells in cyclophosphamide treated patients. ${ }^{77}$ There are some exceptions to this rule, for example, treatments aimed at affecting trafficking of cells into the CNS or decreasing antigen-non-specific inflammatory mediators such as TNF.

19) Effective treatment will require pulse or continuous therapy and ultimately, combination therapy. Until all the factors associated with the disease are known, it is unlikely that a single treatment given once will be effective or a single treatment will be effective in all forms of MS. This is especially true 
if the disease process is being randomly and intermittently triggered by environmental factors. Also it is clear that the disease is more active as viewed by MRI than can be observed clinically: thus continuous or pulse therapy will be required. Furthermore, although there are now treatments that can ameliorate MS, they are only partially effective. Effective therapy will require combination therapy. Combination therapy has been the rule in medicine and one would expect the same to be true for MS. Furthermore, if the immune system is constantly being driven towards a Thl response in MS patients, continuous or pulse therapy will be required to counterbalance this effect unless a more permanent change in the immune system can be induced.

20) The identification of immune measures that are linked to clinical course will be the cornerstone of immunotherapy of MS. If MS is truly an immune mediated disease, and immune therapy is effective, then the ultimate proof of this hypothesis will be the identification of immune measures that are linked both to clinical course and to response to therapy. A major effort in MS by investigators is in attempt to find immune surrogate markers that link to disease activity and/or response to therapy. ${ }^{44,75,76.78}$ Such immune measures would also provide a rationale for which type of combination therapy to administer and when to initiate or stop a particular treatment.

21) Because MS is a multifactorial and heterogeneous disease there will be responders and non-responders to each "effective" therapy. The earlier treatment is initiated, the more likely it is to be effective. It has sometimes been assumed that if a treatment is found for MS it should help all patients. However, I believe a very important treatment concept in MS is that there will be responders and non-responders to each "effective" therapy. Thus, because an individual patient does not respond to a particular treatment does not mean that the treatment is ineffective. Furthermore, since the disease is heterogeneous, one of the most important aims of clinical and immunologic research in MS is to understand why people are responders or non-responders. For example, in our studies of pulse cyclophosphamide we recently found that the shorter the length of time a person is chronic progressive correlates with whether they respond to therapy. ${ }^{66}$ Furthermore, as with any disease process in medicine, it would be expected that the disease would be easiest to arrest at early stages and that later stages would be less responsive to therapy. Towards this end, we are beginning to test the use of 6 months of "rescue therapy" with pulse cyclophosphamide in relapsing-remitting patients that are beta-interferon non-responders. Clearly, one of the primary goals of therapy is to prevent the progressive forms of the disease. This is especially true for immune therapy as it would not be effective to treat axonal damage to the nervous system. Furthermore, if the immune system becomes differentially activated in the progressive forms of the illness, ${ }^{53}$ treatment that is effective in the relapsing stage may not be effective in the progressive stages. Finally, MS may be a more irreversible disease that previously appreciated since axonal transection occurs in MS lesions. ${ }^{79}$

\section{SUMMARY}

The hypothesis outlined above argues that MS is a cell-mediated autoimmune disease driven in an intermittent fashion by the environment in a susceptible host. Thus, the major advances in treatment of MS will come from a better understanding of the immune mechanisms associated with triggering and perpetuating the autoimmune response and devising treatments that effectively and in a relatively non-toxic manner modulate it. What could be missing from this hypothesis? If a chronic infectious agent is discovered in MS (either in the nervous system or the periphery), it would then focus research on ways to modify the infection. Also, MS could theoretically be a primary disease of a CNS component such as the oligodendrocyte or microgial cell with a secondary inflammatory responses. ${ }^{80}$ The $\mathrm{Th} 1 / \mathrm{Th} 2 / \mathrm{Th} 3$ paradigm as presented may be oversimplified as there could be instances in which cytokines have paradoxial effects. Also, there have been treatments postulated to help MS that have not been successful (eg., anti-TNF therapy) and I have not addressed the important areas of remyelination, CNS regeneration or symptomatic treatment of MS. If the immune hypothesis is correct, it must be shown that specific immune changes which occur following immune intervention are linked to clinical response. In this regard, immune intervention also has the potential to activate rather than suppress the pathogenic immune response. Even as we understand more about the disease, MS will never be totally predictable in an individual patient because it is triggered by random environmental events. Furthermore, certain forms of MS and later stages of MS may not be ameliorated by immune therapy. However, it now appears likely that in the coming years effective immunotherapy will be available for a large proportion of MS patients.

\section{ACKNOWLEDGEMENTS}

Supported by NIH grants NS23132, a grant from the National Multiple Sclerosis Society, The Foundation for Neurological Diseases and The Nancy Davis Center Without Walls. I thank my colleagues at the Center for Neurologic Diseases, and David Hafler, David Dawson, Samia Khoury and Vijay Kuchroo, for their helpful discussions and with whom I have had the privilege of working over the years on the investigation of multiple sclerosis. I also thank Deana Genovese for editorial support.

\section{REFERENCES}

1. Martin R, McFarland HF and McFarlin DE. Immunological aspects of demyelinating diseases. Annu Rev Immunol 1992; 10: 153187.

2. Raine CS. The Dale McFarlin memorial lecture. The immunology of the MS lesion. Ann Neurol 1994; 36: S61-S72.

3. Prineas JW. Pathology of Multiple Sclerosis. In: S. D. Cook eds. Handbook of Multiple Sclerosis. Newark: Marcel Dekker, Inc., 1996: 223-255.

4. Lassmann H. Comparative neuropathology of chronic experimental allergic encephalomyelitis and multiple sclerosis. eds. Berlin: Springer-VerlaG, 1983.

5. Windhagen A, Newcombe J, Dangond F, et al. Expression of costimulatory molecules B7-1 (CD80), B7-2 (CD86), and interleukin 12 cytokine in multiple sclerosis lesions. J Exp Med 1995; 182: 1985-1996.

6. Olsson T, Wang W-Z, Höjeberg B, et al. Autoreactive T-lymphocytes in multiple sclerosis determined by antigen-induced secretion of interferon-gamma. J Clin Invest 1990; 86: 981-985.

7. Allegretta M, Nicklas J, Sriram S, Albertini R. T cells responsive to myelin basic protein in patients with multiple sclerosis. Science 1990; 247: 718

8. Zhang J, Markovic S, Raus J, et al. Increased frequency of IL-2 responsive $T$ cells specific for myelin basic protein and proteolipid protein in peripheral blood and cerebrospinal fluid of patients with multiple sclerosis. J Exp Med 1993; 179: 973-984. 
9. Bieganowska KD, Ausubel LJ, Modabber Y, et al. Direct ex vivo analysis of activated, fas-sensitive autoreactive $T$ cells in human autoimmune disease. J Exp Med 1997; 185: 1585-1594.

10. Warren KG, Catz I, Johnson E, Mielke B. Anti-myelin basic protein and anti-proteolipid protein specific forms of multiple sclerosis. Ann of Neurol 1994; 35: 280-289.

II. Linington C, Bradi M, Lassmann H, Brunner C, Vass K. Augmentation of demyelination in rat acute allergic encephalomyelitis by circulating mouse monclonal antibodies directed against a myelin/oligodendrocyte glycoprotein. Am J Pathol 1988; 130: 443-454.

12. Schluesener $H$, Sobel R, Linington $C$, Weiner HL. A monoclonal antibody against a myelin oligodendrocyte glycoprotein induces relapses and demyelination in CNS autoimmune disease. J Immunol 1987; 139: 4016-4021.

13. Lehmann P, Forsthuber T, Miller A, Sercarz E. Spreading of T-cell autoimmunity to cryptic determinants of an autoantigen. Nature 1992; 358: 155 .

14. McCarron R, Fallis R, McFarlin D. Alterations in $T$ cell antigen specificity and class II restriction during the course of chronic relapsing experimental allergic encephlomyelitis. J Neuroimmunol 1990; 29: 73-79.

15. Cross AH, Tuohy VK, Raine CS. Development of reactivity to new myelin antigens during chronic relapsing autoimmune demyelination. Cell Immunol 1993; 146: 261-270.

16. Kaufman DI, Clare-Salzler M, Tian, et al. Spontaneous loss of Tcell tolerance to glutamic acid decarboxylase in murine insulindependent diabetes. Nature 1993; 366: 69-72.

17. Tisch R, Yang X-D, Singer SM, et al. Immune response to glutamic acid decarboxylase correlates with insulitis in non-obese diabetic mice. Nature 1993; 366: 72-75.

18. Kerlero de Rosbo N, Milo R, Lees MB, et al. Reactivity to myelin antigens in multiple sclerosis: peripheral blood lymphocytes respond predominantly to myelin oligodendrocyte glycoprotein. J Clin Invest 1993; 92: 2602-2608.

19. Harrison LC. Islet cell antigens in insulin-dependent diabetes: Pandora's box revisited. Immunol Today 1992; 13: 348-352.

20. Shimonkevitz R, Colburn C, Burnham J, Murray RS, Kotzin BL. Clonal expansion of activated gamma/delta $T$ cells in recent onset multiple sclerosis. Proc Natl Acad Sci U S A 1993; 90: 923-927.

21. Wucherpfennig KW, Newcombe J, Kebby C, Cuzner ML, Hafler DA. Gamma/delta $T$ cell receptor repertoire in acute demyelinating multiple sclerosis lesions. Proc Natl Acad Sci U S A 1992; 89: 4588-4592.

22. Panitch HS, Hirsch RL, Haley AS, Johnson KP. Exacerbations of multiple sclerosis in patients treated with gamma interferon. Lancet 1987; 1: 893-895.

23. Seder RA, Paul WE. Lymphocyte responses and cytokines. Cell 1994; 76: 241-251

24. Racke MK, Bonomo A, Scott DE, et al. Cytokine-induced immune deviation as a therapy for inflammatory autoimmune disease. $J$ Exp Med 1994; 180: 1961-1966.

25. Groux H, O'Garra A, Bigler M, et al. A CD4+ T-cell subset inhibits antigen-specific $T$-cell responses and prevents colitis. Nature 1997; 389: 737-742.

26. Chen Y, Kuchroo VK, Inobe J-I, Hafler DA, Weiner HL. Regulatory $T$ cell clones induced by oral tolerance: suppression of autoimmune encephalomyelitis. Science 1994; 265: 1237-1240.

27. Khoury SJ, Hancock WW, Weiner HL. Oral tolerance to myelin basic protein and natural recovery from experimental autoimmune encephalomyelitis as associated with downregulation of inflammatory cytokines and differential upregulation of transforming growth factor $\beta$, interleukin 4 , and prostaglandin $E$ expression in the brain. J Exp Med 1992; 176: 1355-1364

28. Karpus W, Swanborg R. CD4+ suppressor cells inhibit the function of effector cells of experimental autoimmune encephalomyelitis through a mechanism involving transforming growth factor beta. J Immunol 1991; 146: 1163-1168.

29. Steinman L. Multiple sclerosis and its animal models: the role of the major histocompatibility complex and the $\mathrm{T}$ cell receptor repertoire. Semin Immunopathol 1992; 14: 79-93.
30. Zipp F, Weber F, Huber S, et al. Genetic control of multiple sclerosis: increased production of lymphotoxin and tumor necrosis factor- $\alpha$ by HLA-DR2+ T cells. Ann Neurol 1995; 38: 723-730.

31. Segal BM, Shevach EM. IL-12 unmasks latent autoimmune disease in resistant mice. J Exp Med 1996; 184: $771-775$.

32. Maron R, Hancock W, Slavin A, et al. Genetic susceptibility or resistance to EAE in MHC identical mice is linked to differential cytokine production. FASEB 1997; LB60 (Abst):

33. Mussener A, Lorentzen JC, Kleinau S, Klareskog L. Altered Th1/Th2 balance associated with non-major histocompatibility complex genes in collagen-induced arthritis in resistant rat strains. Eur J Immunol 1997; 27: 695-699.

34. Kuchroo V, Prabhu Das M. Brown JA, et al. B7-1 and B7-2 costimulatory molecules differentially activate the Th1/Th2 developmental pathways: application to autoimmune disease therapy. Cell 1995; 80: 707-718.

35. Oro AS, Guarino TJ, Driver R, Steinman L, Umetsu DT. Regulation of disease susceptibility: decreased prevalence of IgE- mediated allergic disease in patients with multiple sclerosis. J Allergy Clin Immunol 1996; 97: 1402-1408

36. Sadovnick AD, Rice GP, Armstrong H. A population-based study of multiple sclerosis in twins: update. Ann Neurol 1993; 33: 281. 285

37. Kurtzke JF. Epidemiology of multiple sclerosis. In: Vinken PJ, Bruyn GW, Klawans HL, et al., eds. Handbook of Clinical Neurology. New York: Elsevier Science Publishers, 1985: 259-287.

38. Bamford CR, Sibley WA, Thies C. Seasonal variation of multiple sclerosis exacerbations in Arizona. Neurology 1983; 33: 897. 701 .

39. Balashov KE, Olek MJ, Khoury SJ, Weiner HL. Seasonal variation of IFN- $\gamma$ production in progressive multiple sclerosis. AAN 1998 Scientific Program: Neurology (Abst) 1998.

40. Cook SD, Rohowsky-Kochan C, Bansil S, Dowling PC. Evidence for a viral etiology of multiple sclerosis. In: Cook SD, eds. Handbook of Multiple Sclerosis. Newark: Marcel Dekker, Inc., 1996: 97-118.

41. Antel J, Arnason B, Medof M. Suppressor cell function in multiple sclerosis: correlation with clinical disease activity. Ann Neurol 1978; 5: 338-342.

42. Hafler DA, Weiner HL. Immunologic mechanisms and therapy in multiple sclerosis. Immunol Rev 1995; 144: 75-107.

43. Hafler DA, Weiner HL. In vivo labeling of peripheral blood T-cells using monoclonal antibodies: rapid traffic into cerebrospinal fluid in multiple sclerosis. Ann Neurol 1987; 22: 90-93.

44. Bongioanni P, Meucci G. T-cell tumor necrosis factor-alpha receptor binding in patients with multiple sclerosis. Neurology 1997; 48: 826-831.

45. Noronha A, Toscas A, Jensen MA. Interferon beta augments suppressor cell function in multiple sclerosis. Ann Neurol 1990; 27 207-210.

46. Hafler D, Fox D, Manning M, et al. In vivo activated $T$ lymphocytes in the peripheral blood and cerebrospinal fluid of patients with multiple sclerosis. N Engl J Med 1985; 312: 1405-1411.

47. Berger T, Weerth S, Kojima K, et al. Experimental autoimmune encephalomyelitis: The antigen specificity of $T$ lymphocytes determines the topography of lesions in the central and peripheral nervous system. Laboratory Investigation 1997; 76: 355-364.

48. Revesz T, Kidd D, Thompson AJ, et al. A comparison of the pathology of primary and secondary progressive multiple sclerosis. Brain 1994; 117: 759-765.

49. Schmied M, Breitschopf H, Gold R, et al. Apoptosis of T lymphocytes in experimental autoimmune encephalomyelitis. Evidence for programmed cell death as a mechanism to control inflammation in the brain. Am J Pathol 1993; 143: 446-452.

50. Kennedy MK, Torrance DS, Picha KS, Mohler KM. Analysis of cytokine mRNA expression in the central nervous system of mice with experimental autoimmune encephalomyelitis reveals that IL-10 mRNA expression correlates with recovery. J Immunol 1992; 149: 2496-2505.

51. Chen Y, Hancock WW, Marks R, Gonnella PA, Weiner HL. Mechanisms of recovery from experimental allergic encephalomyelitis: $T$ cell deletion and immune deviation in myelin basic protein receptor transgenic mice. J Neuroimmunol 1998; in press. 
52. Correale J, Gilmore W, McMillan M, et al. Patterns of cytokine secretion by autoreactive proteolipid protein-specific $\mathrm{T}$ cell clones during the course of multiple sclerosis. J Immunol 1995; 154: 2959-2968.

53. Balashov KE, Smith DR, Khoury SJ, Hafler DA, Weiner HL. Increased IL-12 production in progressive multiple sclerosis: Induction by activated CD4+ T cells via CD40 ligand. Proc Natl Acad Sci U S A 1997; 94: 599-603.

54. Comabella M, Balashov K, Smith D, Weiner HL, Khoury SJ. Cyclophosphamide treatment normalizes the increased IL-12 production in patients with chronic progressive MS and induces a Th2 cytokine switch. AAN Scientific Program: Neurology (Abst) 1998.

55. Miller DH, Grossman RI, Reingold SC, McFarland HF. The role of magnetic resonance techniques in understanding and managing multiple sclerosis. Brain (1998); 121: 3-24.

56. Khoury SJ, Guttman CRG, Orav EJ, et al. Longitudinal MRI imaging in multiple sclerosis: correlation between disability and lesion burden. Neurology 1994; 44: 2120-2124.

57. Filippi M, Horsfield MA, Morrissey SP. Quantitative brain MRI lesion load predicts the course of clinically isolated syndromes suggestive of multiple sclerosis. Neurology 1994; 44: 635-641.

58. Weiner HL, Khoury SJ, Guttmann C, et al. Magnetic resonance imaging correlates with clinical disability and attacks in multiple sclerosis. AAN Scientific Program: Neurology (Abst) 1998.

59. Losseff NA, et al. Spinal cord atrophy and disability in multiple sclerosis: A new reproducible and sensitive MRI technique with potential to monitor disease progression. Brain 1996; 119: 101-108.

60. van Walderveen MA, Barkhof F, Hommes OR, et al. Correlating MRI and clinical disease activity in multiple sclerosis: relevance of hypointense lesions on short-TR/short-TE (T1-weighted) spin-echo images. Neurology 1995; 45: 1684-1690.

61. Martin R, McFarland HF. Immunological aspects of experimental allergic encephalomyelitis and multiple sclerosis. Crit Rev Clin Lab Sci 1995; 32: 121-182.

62. Lublin FD, Knobler RL, Kalman B, et al. Monoclonal anti-gamma interferon antibodies enhance experimental allergic encephalomyelitis. Autoimmunity 1993; 16: 267-274.

63. Ferber IA, Brocke S, Taylor-Edwards $C$, et al. Mice with disrupted IFN- $\gamma$ gene are susceptible to the induction of experimental autoimmune encephalomyelitis (EAE). J Immunology 1996; 156: 5-7.

64. Billiau A, Heremans H, Vandekerckhove F, et al. Enhancement of experimental allergic encephalomyelitis by antibodies against IFN- $\gamma$. J Immunol 1988; 140: 1506-1510.

65. Weiner H, Hohol M, Khoury S, Dawson D, Hafler D. Therapy for MS. Neurologic Clinics 1995; 13: 173-196.

66. Hohol MJ, Olek MJ, Orav EJ, et al. Treatment of progressive multiple sclerosis with pulse cyclophosphamide/methylprednisolone: response to therapy is linked to duration of progressive disease. AAN Scientific Program: Neurology (Abst) 1998.

67. Weiner HL. Oral tolerance: immune mechanisms and treatment of autoimmune diseases. Immunol Today 1997; 18: 335-343.

68. Fukaura H, Kent SC, Pietrusewicz MJ, et al. Induction of circulating myelin basic protein and proteolipid protein-specific transforming growth factor-betal-secreting Th 3 T cells by oral administration of myelin in multiple sclerosis patients. J Clin Invest 1996; 98; 70-77.

69. Nicholson L, Greer J, Sobel R, Lees M, Kuchroo V. An altered peptide ligand mediates immune deviation and prevents EAE. Immunity 1995; 3: 397-405.

70. Miller A, Lider O, Weiner HL. Antigen-driven bystander suppression following oral administration of antigens. J Exp Med 1991; 174: 791-798.

71. Al-Sabbagh A, Miller A, Santos LMB, Weiner HL. Antigen-driven tissue-specific suppression following oral tolerance: orally administered myelin basic protein suppresses proteolipid induced experimental autoimmune encephalomyelitis in the SJL mouse. Eur J Immunol 1994; 24: 2104-2109.

72. von Herrath MG, Dyrberg T, Oldstone MBA. Oral insulin treatment suppresses virus-induced antigen-specific destruction of beta cells and prevents autoimmune diabetes in transgenic mice. J Clin Invest 1996; 98: 1324-1331.
73. Becker KJ, McCarron RM, Ruetzler C, et al. Immunologic tolerance to myelin basic protein decreases stroke size after transient focal cerebral ischemia. Proc Natl Acad Sci U S A 1997; 94: 1087310878.

74. Aharoni R, Teitelbaum D, Sela M, Arnon R. Copolymer 1 induces T cells of the $T$ helper type 2 that crossreact with myelin basic protein and suppress experimental autoimmune encephalomyelitis. Proceedings of the National Academy of Science, USA 1997; 94: 10821-10826.

75. Smith D, Balshov K, Hafler D, Khoury S, Weiner H. Immune deviation following cyclophosphamide/ methylprednisolone treatment of multiple sclerosis: Increased IL-4 and associated eosinophilia. Ann Neurol 1997; 42: 313-318.

76. Rudick R, Ransohoff R, Peppler R. Interferon beta induces IL-10 expression: relevance to multiple sclerosis. Ann Neurol 1996; 40: 618-627.

77. Takashima H, Smith DR, Fukaura H, et al. Cyclophosphamide induces myelin antigen specific IL-4 secreting T cells in multiple sclerosis patients. Clin Immunol Immunopath 1998: in press.

78. Genc K, Dona D, Reder AT. Increased CD80+ B cells in active multiple sclerosis and reversal by interferon $\beta$-lb therapy. J Clin Invest 1997; 99: 2664-2671.

79. Trapp BD, Peterson J, Ransohoff RM, et al. Axonal transection in the lesions of multiple sclerosis. N Engl J Med 1998; 338; 278285.

80. Sriram S, Rodriguez M. Indictment of the microglia as the villain in multiple sclerosis. Neurology 1997; 48: 464-470.

81. Yudkin PL, Ellison GW, Ghezzi A, et al. Overview of azathioprine treatment in multiple sclerosis. The Lancet 1991; 338: 10511055.

82. Durelli L, Bongioanni MR, Ferrero B, et al. Interferon alpha-2a treatment of relapsing-remitting multiple sclerosis: disease activity resumes after stopping treatment. Neurology 1996; 47: 123129.

83. Jacobs L, Cookfair D, Rudick R, et al. Results of a phase III trial of intramuscular recombinant beta interferon as treatment for multiple sclerosis. Ann Neurol 1994; 36: 259.

84. The IFNB Multiple Sclerosis Study Group and the University of British Columbia MS/MRI Analysis Group. Interferon beta- $1 \mathrm{~b}$ in the treatment of multiple sclerosis: Final outcome of the randomized controlled trial. Neurology 1995; 45: 1277-1285.

85. Beutler E, Sipe JC, Romine JS, et al. The treatment of chronic progressive multiple sclerosis with cladribine. Proc Natl Acad Sci U S A 1996; 93: 1716-1720.

86. Johnson KP, Brooks BR, Cohen JA, et al. Copolymer I reduces relapse rate and improves disability in relapsing-remitting multiple sclerosis: Results of a phase III multicenter, double-blind, placebo-controlled trial. Neurology 1995; 45: 1268-1276.

87. Beck RW, Cleary PA, Trobe JD, et al. The effect of corticosteroids for acute optic neuritis on the subsequent development of multiple sclerosis. NEJM 1993; 239: 1764-1769.

88. Weiner HL, Mackin GA, Orav EJ, et al. Intermittent cyclophosphamide pulse therapy in progressive multiple sclerosis: final report of the Northeast Cooperative Multiple Sclerosis Treatment Group. Neurology 1993; 43: 910-918.

89. Hommes OR, Lamers KJB, Reekers P. Effect of intensive immunosuppression on the course of chronic progressive multiple sclerosis. J Neurol 1980; 223: 177-190.

90. Multiple Sclerosis Study Group. Efficacy and toxicity of cyclosporine in chronic progressive multiple sclerosis: a randomized, double-blinded, placebo-controlled clinical trial. Ann Neurol 1990; 27: 591-605.

91. Fazekas F, Deisenhammer F, Strasser-Fuchs S, Nahler G, Mamoli B. Randomized placebo-controlled trial of monthly intravenous immunoglobulin therapy in relapsing-remitting multiple sclerosis. Lancet 1997; 349: 589-593.

92. Anderson O, Lycke J, Tollesson PO, et al. Linomide reduces the rate of active lesions in relapsing-remitting multiple sclerosis. Neurology 1996; 47: 895-900.

93. Karussis DM, Meiner Z, Lehmann D, et al. Treatment of secondary progressive multiple sclerosis with the immunomodulator linomide: a double blind, placebo-controlled pilot study with monthly magnetic resonance imaging evaluation. Neurology 1996; 47: 341-346. 
94. Goodkin DE, Rudick RA, VanderBrug Medendorp S. Low-dose $(7.5 \mathrm{mg}$ ) oral methotrexate reduces the rate if progression in chronic progressive multiple sclerosis. Ann Neurol 1995; 37: 30-40.

95. Edan G, Miller D, Clanet M, et al. Therapeutic effect of mitoxantrone combined with methylprednisolone in multiple sclerosis: a randomised multicenter study of active disease using MRI and clinical criteria. J Neurol Neurosurg Psychiatry 1997; 62: 112-118.

96. Weiner HL, Dau PC, Khatri BO, et al. Double-blind study of true vs. sham plasma exchange in patients treated with immunosuppression for acute attacks of multiple sclerosis. Neurology 1989; 39: $1143-1149$
97. Rodriguez M, Karnes WE, Bartleson JD, Pineda AA. Plasmpheresis in acute episodes of fulminant CNS inflammatory demyelination. Neurology 1993; 43: 1100-1104.

98. Cook SD, Devereux C, Troiano R, et al. Total lymphoid irradiation in multiple sclerosis. In: Rudick RA, Goodkin DE, eds. Treatment of multiple sclerosis: trial design, results, and future perspectives. New York: Springer-Verlag, 1992: 267-280. 